\title{
Influence of reciprocation and rotary motion on fracture of Oneshape nickel titanium rotary files
}

\author{
Yazdan Shantiaee, ${ }^{1}$ Babak Zandi, ${ }^{2}$ Reza Mofidian ${ }^{3}$ and Negar Norouzi ${ }^{4}$ * \\ ${ }^{1}$ Assistant Professor, Department of Endodontics, School of Dentistry, Shahid Beheshti University of Medical \\ Sciences, Tehran, Iran \\ ${ }^{2}$ Resident, Department of Oral and Maxillofacial Surgery, School of Dentistry, Shahid Beheshti University of \\ Medical Sciences, Tehran, Iran \\ ${ }^{3}$ Postgraduate Student, Department of Endodontics, School of Dentistry, Shahid Beheshti University of \\ Medical Sciences, Tehran, Iran
}

\begin{abstract}
Single file rotary systems are frequently used for preparation root canals due to their speed, single use and decreased contamination possibility, however, file fracture is a main problem in these systems. This study assessed the effects of different reciprocating angles and rotary movements on the fracture resistance of OneShape instruments. 150 mesiobuccal and mesiolingual canals of mandibular molars or mesiobuccal and distobuccal canals of maxillary molars having $30-60^{\circ}$ curvatures were selected and assigned to 3 groups; OneShape files were used with rotary movement, reciprocating movement with $30-150^{\circ}$, reciprocating movement with $30-90^{\circ}$ until they will fracture. The time required for canal preparation, the canal's curvatures, the mean length of fractured segments and the mean number of prepared canals with one file were measured. In rotary movements, in 8 canals (16.0\%) files were fractured, while in the reciprocating movement with 30-150 degree and 30-90 ; in $6(12.0 \%)$ and $5(10.0 \%)$ canals files were fractured, respectively. No significant differences were noted regarding the fracture incidence of 3 groups. The mean time required for canal preparation in OneShape instruments with rotary, reciprocating movements with 30-90 degrees and 30-150 degrees were $31.31 \pm 15.83,62.89 \pm 48.87$ and $46.5 \pm 35.54$ seconds, respectively. The preparation time with rotary movements were significantly lower than reciprocating movements with $30-90^{\circ}(\mathrm{P}=0.001)$. No other significant differences were noted in the paired comparisons. Using OneShape instruments had higher fracture resistance by reciprocating movements with different angles, but it was not significant. The preparation time with rotary movements were significantly lower than reciprocating movements with 30-90.
\end{abstract}

KEY WORDS: FRACTURE RESISTANCE, ROTARY AND RECIPROCATING MOVEMENTS, ONESHAPE INSTRUMENTS

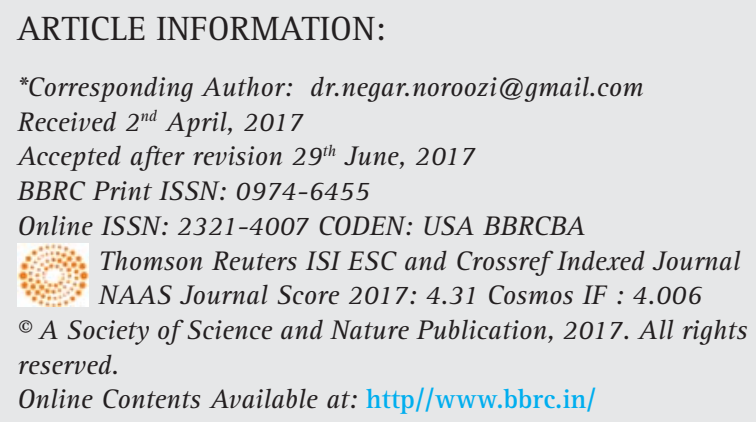




\section{INTRODUCTION}

Nickel titanium (NiTi) rotary files are wide range of biomaterials which have ability to recover original shape after undergoing large deformations through heating (shape memory effect) or removal of the load (super elastic effect) (Ye and Gao, 2012). NiTi files have low elastic modulus and super elasticity compared to stainless steel instruments (Al-Hadlaq et al., 2010). Root canal instrumentation must reserve the existing apical foramen with a flared shape from apical to coronal and not change the original canal curvature (Capar et al., 2014). The OneShape instruments contain of one instrument, which is characterized by different cross-sectional designs over the whole length of the working part. This instrument is made of a conventional austenite NiTi alloy (Burklein et al., 2013). OneShape consists of 3 different cross-sectional zones; in the first zone at the tip region, the cross section is characterized by a 3-cutting edge design, in the last zone at the shank, the S-shaped cross section shows 2 cutting edges (Saber et al., 2014).

Instrument fracture is a serious problem which can affects root canal treatment. It is reported more than $50 \%$ of dentists had experience of complications during or after removal of fractured files (Castelló-Escrivá et al., 2012). The removal of ledges, canal transportations and root perforations are the most common complications (Castelló-Escrivá et al., 2012). A major concern with use of NiTi engine-driven rotary instruments is fracture (Sattapan et al., 2000). Fracture of endodontic rotary instruments occurs by torsional and flexural fracture (Sattapan et al., 2000). Torsional strength reveals the capability of the file to twist before fracture and is required in the preparation of narrow and constricted canals because the file is susceptible to high torsional loads (Elsaka and Elnaghy, 2015). On the other hand, flexibility is essential for curved canals. An instrument with great flexibility may result in less undesirable variations in the shape of curved canals and improvements cyclic fracture resistance (Elnaghy et al., 2015).

Despite considerable improvements were done in file design and manufacturing methods, file separation caused by cyclic fracture is remained a major concern (Hsieh et al. 2010). Also, several factors such as cross-sectional shape, diameter, mass, flute depth and taper influence the fracture life of the files (Elsaka and Elnaghy, 2015).

Rotary and single-file systems are frequently used for the preparation of root canals due to their speed, single use and decreased contamination possibility, however, file fracture is a main problem in these systems (Arias et al., 2012). Reciprocating systems are developed to overcome this problem, in which, two-sided movements decrease the torsional and flexural fracture of the instruments leading to decreased file fracture (Dagna et al.,
2014). Rotation of endodontic instruments subjects them to tensile and compressive forces in the curvature of the canal (Bhagabati et al., 2012). Numerous studies have proved that reciprocation motion improved the cyclic fracture resistance of files (Pedullà et al., 2013; Vadhana et al., 2014). It is reported rotary files with reciprocating motion increases the fracture life of an instrument (Yared et al. 2008). In reciprocating movement, the instrument rotates in clickwise and counterclockwise direction before completing a full rotary cycle (Wan et al., 2011; Ferreira et al., 2016).

Despite previous reports, there is concern about application of the continuous or reciprocating movements on cyclic fracture (Plotino et al., 2015). However, there is not enough information about influence of reciprocation and rotary motions on the fracture of Ni-Ti rotary files. So, the aim of the current study was to determine effects of rotary and reciprocating movements with different movement angles on the fracture resistance of OneShape Ni-Ti instruments.

\section{MATERIAL AND METHODS}

In this in vitro experimental study, OneShape files (Micro Mega, Besanc, France) (25, 6\%) were selected. By using SEM (VEGA2, TESCAN, Czech) at $\times 20$, each instrument was examined for defects before the test. Then OneShape samples were randomly divided into 3 groups. In group 1, OneShape files were used by rotary movement ( $350 \mathrm{rpm}$, torque $2 \mathrm{~N} / \mathrm{Cm}$ ). In group 2, OneShape files were operated by reciprocating movement with $30-90^{\circ}$ (350 rpm). In group 3, OneShape files were operated by reciprocating movement with $30-150^{\circ}$ (350 rpm). Based on previous study (Pedulla et al., 2013) 150 mesiobuccal and mesiolingual canals of mandibular molars or mesiobuccal and distobuccal canals of maxillary molars having $30-60^{\circ}$ curvatures with ability of K-file \# 10 (Mani,Japan) insertion into the entire of the canal, Vertucci type 1 canal and with no $S$ curve were selected. All teeth were located into $\mathrm{NaOCl}$ (5.25\%) for 30 minutes and then transferred into normal saline (Lee et al. 2013). At first glidepath was done using K-file no. 10 and after observation of the file from root apex , the length was measured by subtracting $1 \mathrm{~mm}$ from that point. Determination of canal curvature was done by Schneider technic (Schneider, 1971). All shaping procedure was done using Acteon motor (Acteon,North America) by hanpase $1: 6$ and pecking movement $(3 \mathrm{~mm})$ until they will fracture (Gavini et al. 2012). The files' fracture incidence was calculated in each group when preparing total 50 canals. Preparation of the canals was done with RcPrep (MD-ChelCream, META BIOMED COLTD, Korea). The time required for the tooth preparation, the canal's curvatures, the mean length of fractured segments and 


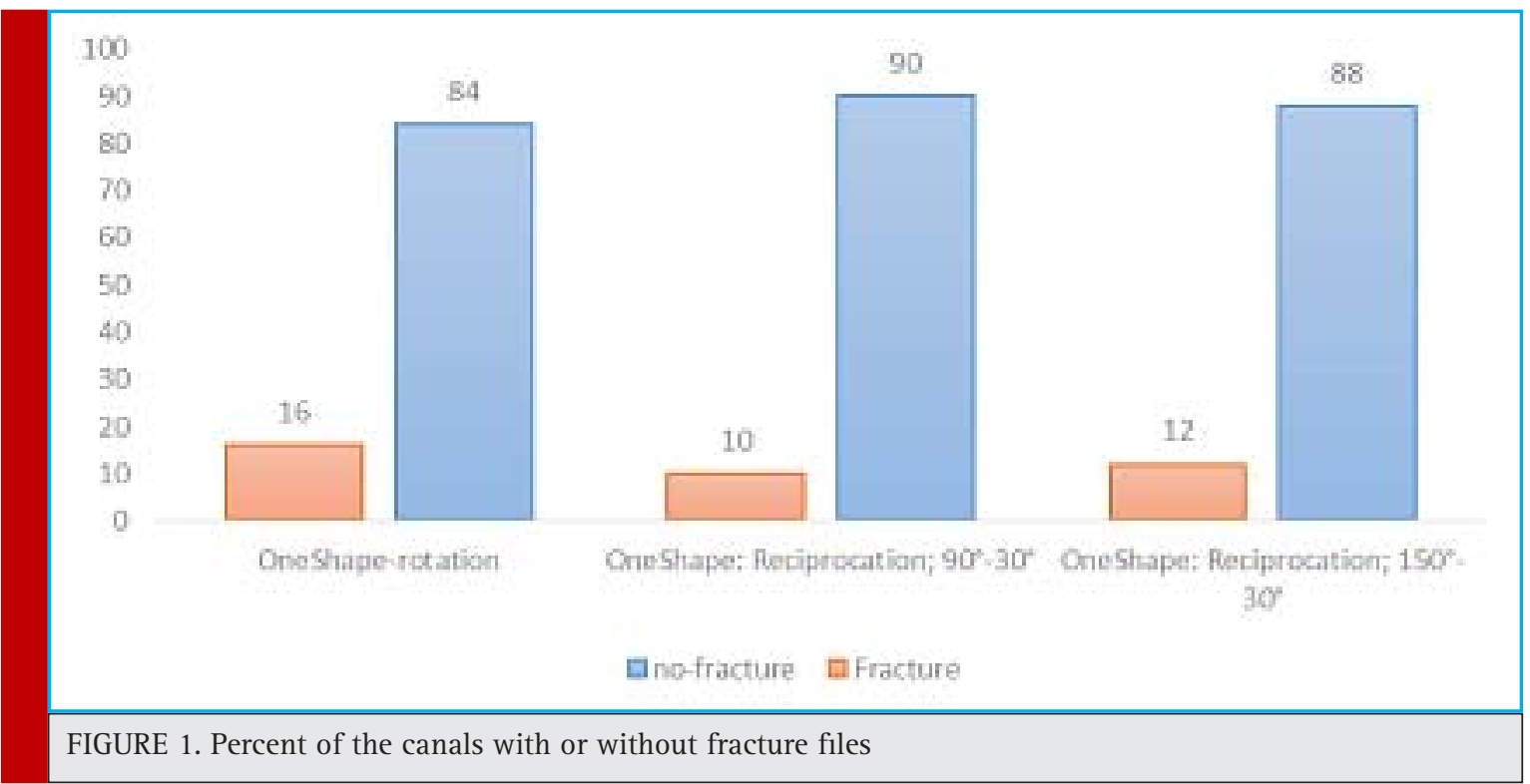

the mean number of prepared canals with one file were measured also. After insertion the fractured section into ultrasonic bath (CODYSON, China) for 5 minutes, they evaluated by scanning electron microscope (SEM).

\section{STATISTICAL ANALYSIS}

Fracture incidence rates were statistically analyzed by chi-square test among 3 groups while the time of tooth preparation and the canal curvature were subjected to one-sided analysis of variance test using the software SPSS 16.0 for Windows. The paired comparisons were done by Tukey test. $\mathrm{P}<0.05$ was considered as significant difference between groups.

\section{RESULTS}

The results of influence of rotary and reciprocation movement using various angle on fracture of NiTi rotary files is present in figure 1. According to figure 1, in rotary movements, in $8(16.0 \%)$ canals, files were fractured, while in reciprocating movements with 30-150 degree and 30-90 degree; in 6 (12.0\%) and 5 (10.0\%) canals, files were fractured respectively. No significant differences were noted regarding the fracture incidence of 3 groups $(\mathrm{P}>0.05)$.

The results of the time required for canal preparation in OneShape instruments is presented in table 1. According to the results, the time required for canal preparation in OneShape instruments with rotary, reciprocating movements with 30-90 degree and 30-150 degree were $31.31 \pm 15.83,62.89 \pm 48.87$ and $46.5 \pm 35.54$ seconds, respectively. The preparation time of rotary movement were significantly lower than reciprocating movement with 30-90 degree $(\mathrm{P}=0.001)$.

The result for scattering parameters of canal curvature is presented in table 2. As seen, the canal curvature was distributed evenly.

\begin{tabular}{|l|l|l|l|}
\hline \multicolumn{4}{|l|}{ Table 1. Time required for the tooth preparation in OneShape instruments } \\
\hline & Mean \pm Sd & Minimom & Maximum \\
\hline OneShape-rotation & $31.31 \pm 15.83$ & 26.38 & 36.24 \\
\hline OneShape: reciprocating; $30-90^{\circ}$ & $62.89 \pm 48.87$ & 48.21 & 77.57 \\
\hline OneShape: reciprocating; $30-150^{\circ}$ & $46.5 \pm 35.54$ & 35.69 & 57.31 \\
\hline
\end{tabular}

\begin{tabular}{|l|l|l|l|}
\hline \multicolumn{4}{|l|}{ Table 2. The scattering parameters of the curvature } \\
\hline & Mean \pm Sd & Maximum & Minimum \\
\hline OneShape-rotation & $43.60 \pm 12.19$ & 47.07 & 40.13 \\
\hline OneShape: reciprocating; $30-90^{\circ}$ & $42.3 \pm 12.79$ & 45.94 & 38.66 \\
\hline OneShape: reciprocating; $30-150^{\circ}$ & $43.48 \pm 11.56$ & 46.77 & 40.19 \\
\hline
\end{tabular}




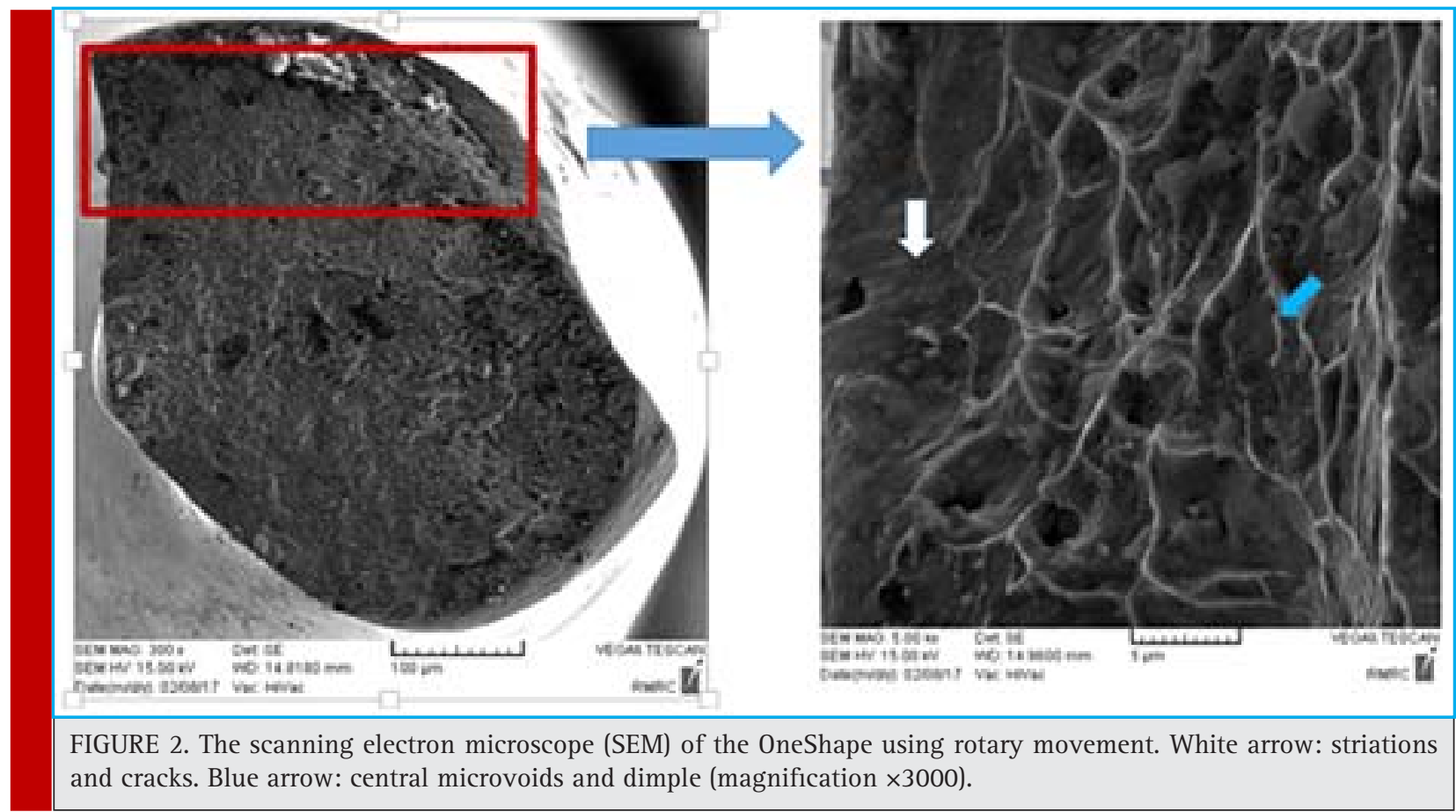

In SEM analyse the characteristic of torsional and flexural fatigue in 3 groups was seen.

The mean length of fractured segments with rotary, reciproc 90-30 and 150-30 degrees motions were $3.75( \pm 1.87), 5( \pm 4.5), 6( \pm 3.25)$, respectively. There was not significant differences between them.The mean number of prepared canals with one file by rotary, recip- roc $90-30$ and $150-30$ degrees motions were $4.75( \pm 3.57)$, $8.4( \pm 4.037), 5.8( \pm 4.4)$, respectively.

\section{DISCUSSION}

Super-elasticity, shape memory effect and corrosion resistance of NiTi alloy provide many advantages for
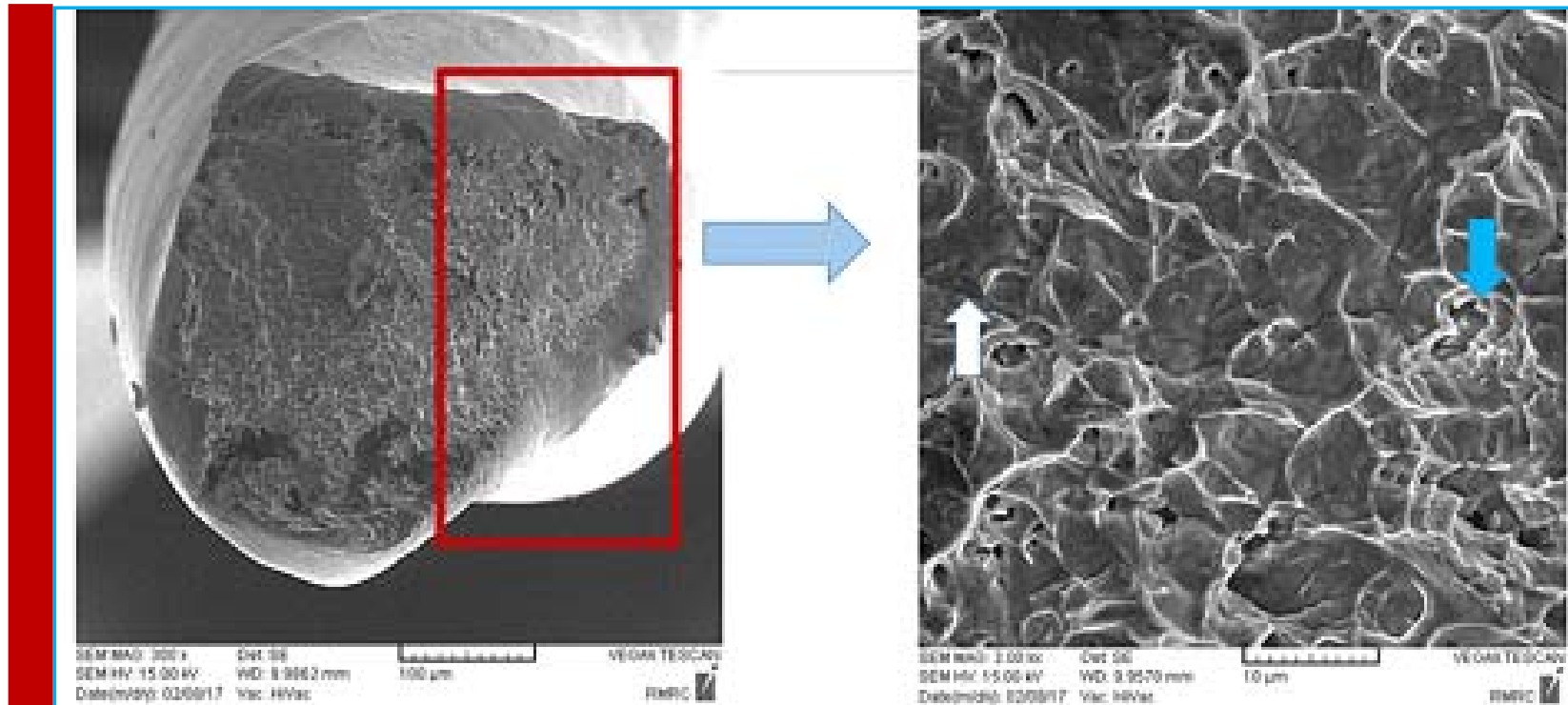

FIGURE 3. The SEM of the OneShape using reciprocating movement with $30-90^{\circ}$. White arrow: striations and cracks. Blue arrow: central microvoids and dimple (magnification $\times 3000$ ). 


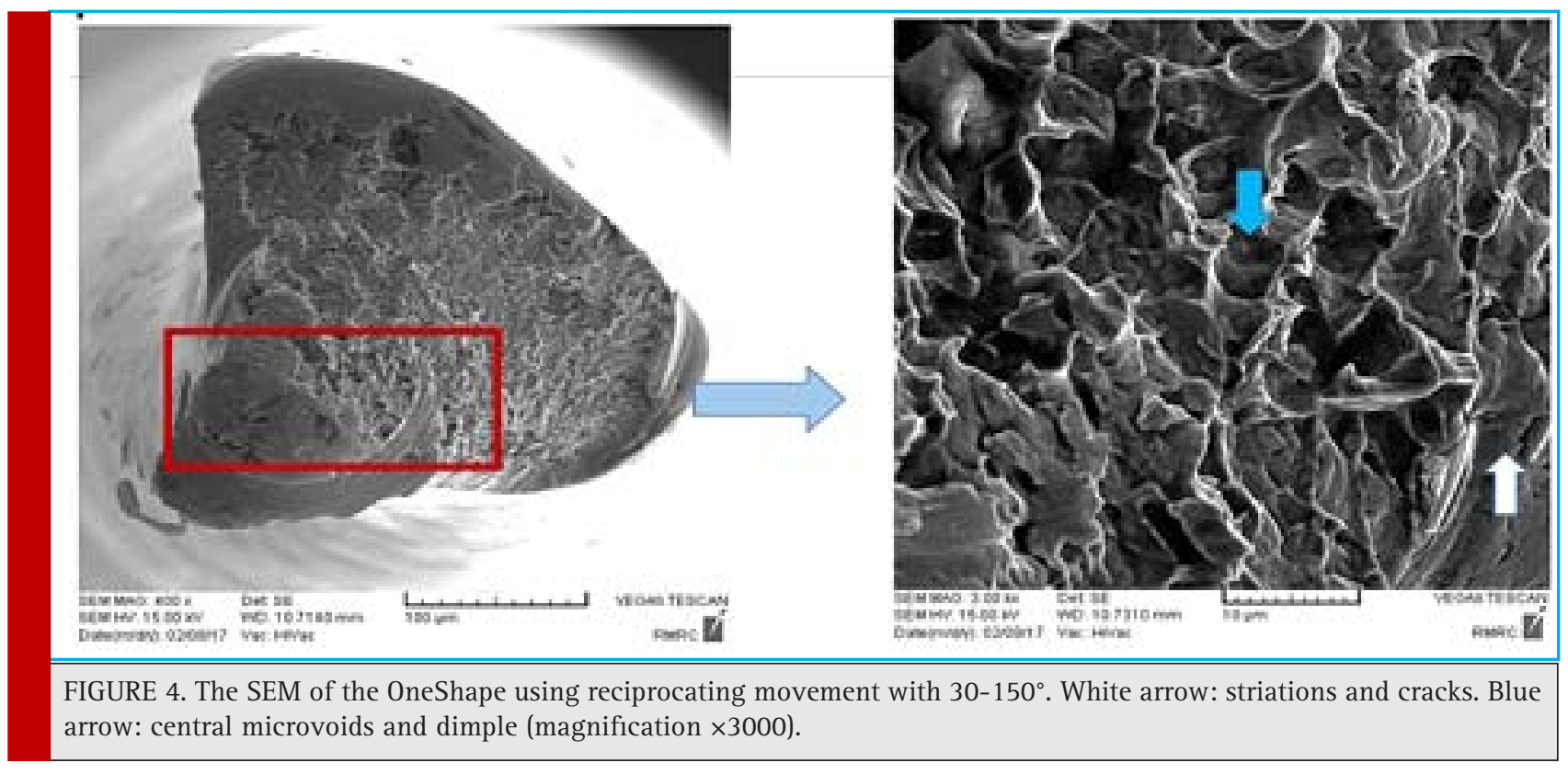

application in dental, medical, and commercial applications (Parashos and Messer, 2006). Rotary file fracture usually occurs because of cyclic fracture near the apical third of root canals (Ye et al., 2012). The microstructure of NiTi instruments plays an essential role on root canal treatment outcome and fracture resistance (Ye et al., 2012). A cost-effective technique for endodontic files is needed to prevent unexpected fracture during root canal treatment procedures (Elsaka and Elnaghy, 2015).

The present study examined the influence of reciprocation and rotary motion on fracture of NiTi rotary files. As observed in this study using OneShape instruments had higher fracture resistance by reciprocating movements with different angles but it was not significant. It is well documented failure of NiTi files is influenced by technique of preparation (Varela-Patiño et al., 2010). Additionally, Varela-Patiñ et al., (2008), reported the instrument fracture incidence in resin blocks was lower using reciprocating motion compared to the continuous rotation. In comparison of the conventional continuous rotation and reciprocating Yared (2008) reported a forward $144^{\circ}$ and backward $72^{\circ}$ reciprocating motion is more cost-effective and time-saving. Additionally, reciprocating movement extended the fracture life of the instrument compared to the conventional rotary movement (Pedulla et al., 2013).

OneShape is made from conventional austenite NiTi alloy (Shen et al., 2006). The reciprocating motion has an advantage for the preparation of curved canals with the use of one single NiTi file instead of the conventional continuous rotation method (Plotino et al., 2012). Based on the results, different angel reciprocating move- ments had no significant effect on the OneShape instruments fracture resistance. In this regard, no significant difference was reported in the fracture cycles by reciprocation $\left(140^{\circ}\right.$ clockwise and $45^{\circ}$ counterclockwise) or continuous rotation for either instrument (Lee et al., 2013). Reciprocal motion would decrease the torsional stress through periodically reversing the rotation $\left(150^{\circ}\right.$ counterclockwise, then $30^{\circ}$ clockwise rotation for Reciproc; $170^{\circ}$ counterclockwise, then $50^{\circ}$ clockwise rotation for WaveOne) (Kim et al., 2012). Extended fracture life reported using new generation One-Shape instruments in reciprocating motions $\left(150^{\circ}\right.$ clockwise $-30^{\circ}$ counterclockwise, $210^{\circ}$ clockwise $-30^{\circ}$ Counterclockwise and $360^{\circ}$ clockwise $-30^{\circ}$ counterclockwise) compared with continuous rotation (Karatas et al., 2016).

The average lifespan of One-Shape file was $-4.63 \pm 1.30$ canals. It is reported WaveOne files has higher resistance to fracture compared with the One Shape files (Karova et al., 2014). In evaluating the cyclic fracture resistance with all the angles $\left(90^{\circ}\right.$ clockwise $/ 30^{\circ}$ counterclockwise, $150^{\circ}$ clockwise $/ 30^{\circ}$ counterclockwise, $210^{\circ}$ clockwise $130^{\circ}$ counterclockwise and $390^{\circ}$ clockwise $/ 30^{\circ}$ counterclockwise), the use of reciprocating motion increased the fracture resistance, compared to conventional rotary motion (Gambarini et al., 2013).

Resistance to cyclic fatigue depends on various factors such as diameter, metal mass, flexibility, cross-sectional shape, regressive surface area, and presence of transitional zones in files. One Shape rotary files could have experienced more stress cycles of tension and compression per minute when compared to two for the same time period (Sekar et al., 2016). It is reported number of 
canals successfully cleaned and shaped with continuous motion were significantly higher than reciprocating motion and less time needed for the preparation using continuous motion than reciprocating motion (Mangat et al., 2016).

It is reported the number of cycles to fracture for instruments under reciprocation motion was higher compared to continuous rotation (Gavini et al., 2012). Also, average time until fracture using reciprocating movement was longer than continuous movement (Gavini et al., 2012). So, It is recommended to use One Shape files with reciprocating motion in a single tooth (Mangat et al., 2016). Although in our study the mean number of prepared canals with one file by rotary, reciproc $90-30$ and $150-30$ degrees motions were $4.75( \pm 3.57)$ , $8.4( \pm 4.037)$, 5.8 \pm 4.4$)$, respectively. In reciprocating movement more cycle rotation is needed for full rotation,because of that the extended fracture life and increased preparation time were seen.

Examination of a fracture surface by the SEM reveals distinct features and helps to identify the type of fracture mechanism (Parashos and Messer, 2006). So, because of that in the current study we used SEM to investigate the fracture section of the files. The microcracks and striations indicate the occurrence of fatigue failure and microvoids and dimples indicate torsional fracture. In conclusion, Using OneShape instruments had higher fracture resistance by reciprocating movements with different angles, but it was not significant. The preparation time with rotary movements was significantly lower than reciprocating movements with $30-90^{\circ}$.

\section{REFERENCES}

Al-Hadlaq, S.M.S., AlJarbou, F.A., AlThumairy, R.I. 2010. Evaluation of cyclic flexural fracture of M-Wire nickel-titanium rotary instruments. J. Endod., 36:305-7.

Arias, A., Pérez-Higueras, J.J., de la Macorra, J.C. 2012. Differences in cyclic fracture resistance at apical and coronal levels of Reciproc and WaveOne new files. J. Endod., 38: 12441248 .

Bhagabati, N., Yadav, S., Talwar, S. 2012. An in vitrocyclic fracture analysis of different endodontic nickel-titanium rotary instruments. J. Endod., 38: 515-518.

Burklein, S., Hinschitza, K., Dammaschke, T., Sch€afer, E. 2012. Shaping ability and cleaning effectiveness of two single-file systems in severely curved root canals of extracted teeth: Recproc and WaveOne versus Mtwo and ProTaper. Inter. Endo. J., 45: 449-61.

Burklein, S., Benten, S., Schafer, E. 2013. Shaping ability of different single-file systems in severely curved root canals of extracted teeth. Inter. Endo. J., 46: 590-597.

Capar, I.D., Ertas, H., Ok, E., Arslan, H., Ertas, E.T. 2014. Comparative study of different novel nickel-titanium rotary sys- tems for root canal preparation in severely curved root canals. J. Endod., 40:852-856.

Castelló-Escrivá, R., Alegre-Domingo, T., Faus-Matoses, V., Román-Richon, S., Faus- Llácer, V.J. 2012. In vitro comparison of cyclic fracture resistance of ProTaper, WaveOne, and Twisted Files. J. Endod., 38:1521-1524.

Dagna, A., Poggio, C., Beltrami, R., Colombo, M., Chiesa, M., Bianchi, S. 2014. Cyclic fracture resistance of OneShape, Reciproc, and Wave0ne: An in vitro comparative study. J. Conserv. Dent., 17:250-254.

Elnaghy, A.M., Elsaka, S.E. 2015. Torsion and bending properties of OneShape and WaveOne instruments. J. Endod., 41:544-547.

Elsaka, S.E., Elnaghy, A.M. 2015. Cyclic fracture resistance of OneShape and WaveOne instruments using different angles of curvature. Dent. Mater. J., 34(3):358-363.

Elsaka, S.E., Elnaghy, A.M. 2015. Torsion and bending properties of OneShape and WaveOne instruments. J. Endod., 41:544-547.

Ferreira, F., Adeodato, C., Barbosa, I., Aboud, L., Scelza, P., Zaccaro Scelza, M. 2016. Movement kinematics and cyclic fracture of NiTi rotary instruments: A systematic review. Int. Endod. J., 50:143-152.

Gambarini, G., Rubini, A.G., Al Sudani, D., Gergi, R., Culla, A., De Angelis, F., Di Carlo, S., Pompa, G., Osta, N., Testarelli. L. 2012. Influence of different angles of reciprocation on the cyclic fracture of nickel-titanium endodontic instruments. J. Endod., 38(10):1408-11.

Gavini, G., Caldeira, C.L., Akisue, E., Candeiro, G.T., Kawakami, D.A. 2012. Resistance to flexural fracture of Reciproc R25 files under continuous rotation and reciprocating movement. J. Endod., 38(5):684-687.

Gavini, G., Caldeira, C.L., Akisue, E., de Miranda Candeiro, G.T., Kawakami, D.A.S. 2012. Resistance to flexural fracture of Reciproc R25 files under continuous rotation and reciprocating movement. J. Endod., 38: 684-7.

Hsieh, S.C, Lee, S.Y., Ciou, C.Y, et al. 2010. Non-destructive natural frequency tests of cyclic fracture-loaded nickel-titanium rotary instruments. Med. Biol. Eng. Comput., 48:555-60.

Karatas, E., Arslan, H., Buker, M., Seckin, F., Capar, I.D. 2016. Effect of movement kinematics on the cyclic fracture resistance of nickel-titanium instruments. Int. Endod. J., 49:361-364.

Karova, E., Topalova-Pirinska, S. 2014. Instrument life of two rotary NitTi single-file techniques with reciprocating and continuous rotation used in curved canals after a glide path creation. J. IMAB - Annual Proceeding (Scientific Papers) 20(1):494499.

Kim, H.C., Kwak, S.W., Cheung, G.S., Ko, D.H., Chung, S.M., Lee, W. 2012. Cyclic fracture and torsional resistance of two new nickel-titanium instruments used in reciprocation motion: Reciproc versus Waveone. J. Endod., 38:541-544.

Lee. W., Hwang, Y.J., You, S.Y., Kim, H.C. 2013. Effect of reciprocation usage of nickel-titanium rotary files on the cyclic fracture resistance. Aust. Endod. J., 39(3): 146-150. 
Mangat, P., Dhingra, A., Singh, A., Muni, S. 2016. Evaluation of the fracture resistance of Ni-Ti files in continuous and reciprocating motion in curved mesial canals of human permanent mandibular molars: An in vitro study. Indian J. Conservative Endod. 1(1):9-12.

Parashos, P., Messer, H.H. 2006. Rotary NiTi instrument fracture and its consequences. J. Endod., 32:1031-1043.

Pedulla, E., Grande, N.M., Plotino, G., Gambarini, G., Rapisarda, E. 2013. Influence of continuous or reciprocating motion on cyclic fracture resistance of 4 different nickel-titanium rotary instruments. J. Endod., 39: 258-61.

Pedullà, E., Grande, N.M., Plotino, G., Gambarini, G., Rapisarda, E. 2013. Influence of continuous or reciprocating motion on cyclic fracture resistance of 4 different nickel-titanium rotary instruments. J. Endod., 39:258-61.

Plotino, G., Grande, N.M., Testarelli, L. 2012. Cyclic fracture of Reciproc and WaveOne reciprocating instruments. Int. Endod. J., 45: 614-618.

Saber, S.E., Nagy, M.M., Schafer, E. 2014. Comparative evaluation of the shaping ability of WaveOne, Reciproc and OneShape single-file systems in severely curved root canals of extracted teeth. Int. Endod. J., 48:109-14.

Sattapan, B., Nervo, G., Palamara, J., Messer, H. 2000. Defects in nickel titanium endodontic rotary files after clinical usage. J. Endod., 26:161-165.

Schafer, E., Erler, M., Dammaschke, T. 2006. Comparative study on the shaping ability and cleaning efficiency of rotary Mtwo instruments. Part 2. Cleaning effectiveness and shaping ability in severely curved root canals of extracted teeth. Inter. Endod. J., 39: 203-12.
Schneider, S.W. 1971. A comparison of canal preparations in straight and curved root canals. Oral Surg. Oral Med. Oral Pathol., 32:271-275.

Sekar, V., Kumar, R., Nandini, S., Ballal, S., Velmurugan, N. 2016. Assessment of the role of cross section on fatigue resistance of rotary files when used in reciprocation. Eur. J. Dent., 10(4):541-545.

Shen, Y., Cheung, G.S., Bian, Z., Peng, B. 2006. Comparison of defects in ProFile and ProTaper systems after clinical use. J. Endod., 32:61-5.

Vadhana, S., SaravanaKarthikeyan, B., Nandini, S., Velmurugan, N. 2014. Cyclic fracture resistance of RaCe and Mtwo rotary files in continuous rotation and reciprocating motion. J. Endod., 40:995-9.

Varela-Patiño, P., Martin Biedma, B., Rodri'guez Nogueria, J, et al. 2008. Fracture rate of nickel-titanium instruments using continuos versus alternating rotation. Endod. Practice Today, 2:193-7.

Varela-Patino, P., Ibanez-Parraga, A., Rivas-Mundina, B. 2010. Alternating versus continuous rotation: a comparative study of the effect on instrument life. J. Endod., 36:157-159.

Wan, J., Rasimick, B.J., Musikant, B.L., Deutsch, A.S. 2011. A comparison of cyclic fracture resistance in reciprocating and rotary nickel-titanium instruments. Aust. Endod. J., 37:122-7.

Yared, G. 2008. Canal preparation using only one Ni-Ti rotary instrument: preliminary observations. Int. Endod. J., 41: 339-44.

Ye, J., Gao, Y. 2012. Metallurgical Characterization of M-Wire Nickel-Titanium shape memory alloy used for endodontic rotary instruments during low-cycle fracture. J. Endod., 38:105-107. 